\title{
Furfural-Based Modification of PET for UV-Blocking Copolymers with Decreased Oxygen Permeability
}

\author{
Asmaa M. Ahmed, Tuomo P. Kainulainen, and Juha P. Heiskanen* \\ Cite This: Ind. Eng. Chem. Res. 2021, 60, 7495-7504 \\ Read Online
}

ABSTRACT: 2,2'-Bifuran-5,5'-dicarboxylic acid (BFDCA), a highly promising biobased diacid monomer, was used to modify poly(ethylene terephthalate) (PET) to obtain copolyesters with increased biocarbon content and improved properties compared with PET. Antimony-catalyzed copolymerization of the bifuran and terephthalate 2-hydroxyethyl esters was used to afford the PETBF copolymers. When compared against PET, these random copolymers with 5,10 , or $15 \mathrm{~mol} \%$ of the bifuran comonomer in the feed (relative to the total amount of the starting esters) showed a slightly elevated glass transition range, higher tensile moduli, enhanced oxygen gas barrier properties, and superior UV blocking while maintaining good

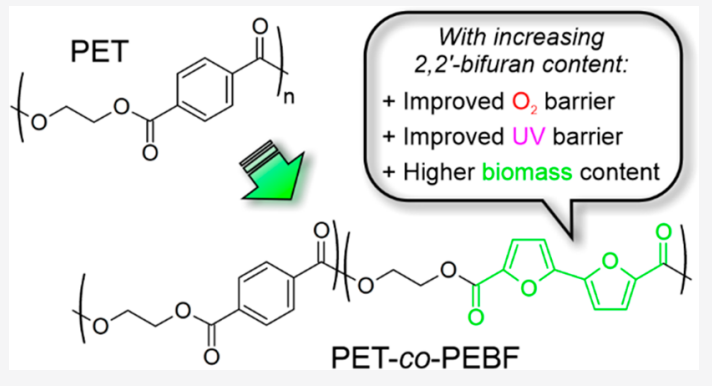
transparency otherwise. Based on our results, PETBF copolyesters seem to have promise as materials with enhanced properties that are desirable in advanced packaging applications.

\section{INTRODUCTION}

Poly(ethylene terephthalate) (PET) has become an ubiquitous material in everyday life as the polymer finds use in diverse packaging applications. The growing global PET production reportedly reached 56 million tons in 2016, while the estimated growth to 70 million tons per year was projected by $2020 .{ }^{1}$ There are several reasons for this steady growth. For example, PET has good mechanical strength, chemical stability, transparency, and injection moldability, in addition to having acceptable barrier properties and competitive efficiency-to-cost ratio. ${ }^{2}$ However, of the main components of PET, ethylene glycol (EG) and terephthalic acid (TA), only ethylene glycol can currently be efficiently produced from biomass sources, ${ }^{3}$ as renewable terephthalic acid is usually much more complicated to produce. ${ }^{4}$ This means that the biocarbon content of PET is mostly limited to $20 \%$, but higher contents are desirable.

Modification of PET with comonomers can be beneficial; e.g., the fast crystallization of PET during certain molding processes is controlled with comonomers introduced into the polymer. Thus, the crystallization rate is slowed down, which is helpful in improving product clarity. ${ }^{5}$ The lower oxygen and carbon dioxide permeabilities of some novel furan-based polyesters, when compared against PET, suggest that PET could be improved in this respect through modification with new renewable monomers, extending its use. ${ }^{6}$ Dramatic improvement in thermal properties has also been reported with biobased isosorbide as a diol comonomer. ${ }^{7}$ Thus, biobased comonomers can provide useful properties in addition to higher biomass content.

Another possible limitation with PET is its UV-light transparency, which can limit its use in the packaging of UVsensitive products. PET blocks UV wavelengths up to around
$315 \mathrm{~nm}$, while more than $50 \%$ transmission can be observed at $330 \mathrm{~nm}$, which is already enough exposure to initiate photooxidative degradation of certain ingredients and affect their shelf life. ${ }^{8}$ Blocking the greatest possible range of damaging UV radiation while at the same time keeping the transmission in the visible region as high as possible is therefore an intriguing property. Generally, UV transmission can be kept below an acceptable level for many applications by using compounds added to the polymer, e.g., UV-absorbing additives or coatings. Despite the effectiveness of additives in polymer production, negative impact on the environment and human health is widely documented in the literature. For instance, additives can contaminate food by migrating from the polymer bulk into the medium in contact with the polymer. ${ }^{9}$ It would therefore be of interest to introduce the UV-blocking moiety directly into the polymer chains themselves, more so with sustainable UV blockers. Based on this strategy, there are only a few reported solutions. One example is lignin, which has been applied as a "green" UV-blocking compound, though the low transmission at UV wavelengths was associated with significantly lowered optical transparency. The broad absorbance of the lignin used and the crystallinity of the aliphatic polyester matrices were probably responsible for the latter. $^{10-14}$ In a more relevant instance, the UV-shielding

Received: February 11, 2021

Revised: April 30, 2021

Accepted: April 30, 2021

Published: May 11, 2021 
Scheme 1. Synthesis of Bis(2-hydroxyethyl)-2,2'-bifuran-5,5'-dicarboxylate and PETBF Copolyesters

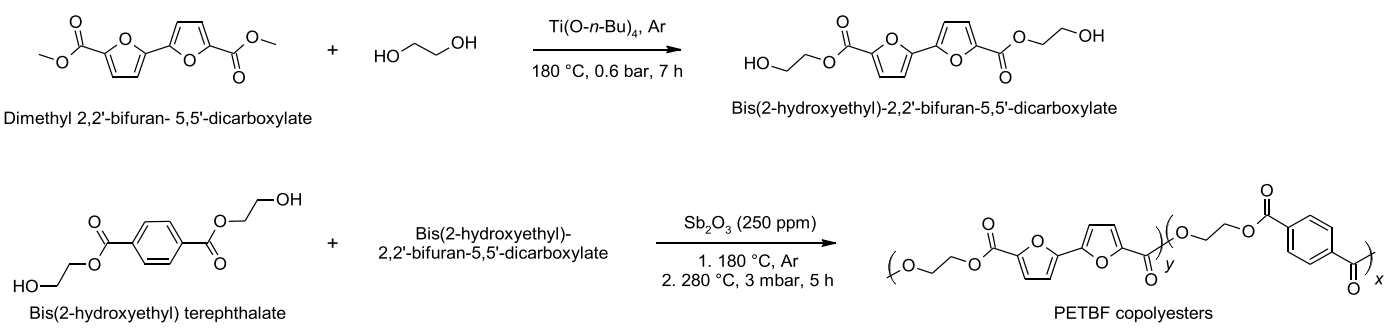

effect in modified PET was produced by the copolymerization with $\alpha$-truxillic acid, a dimer of the naturally occurring cinnamic acid. There, a similar decrease in the film transmittance occurred at both UV and visible wavelengths with increasing $\alpha$-truxillic acid concentrations. ${ }^{15}$

Carbohydrates, e.g., the C5 and C6 sugars derived from hemicellulose and cellulose, respectively, are particularly promising feedstocks for renewable monomers with interesting properties. Specifically, the two central furans, furfural (from C5 sugars) and 5-hydroxymethylfurfural (HMF, from C6 sugars), could become useful raw materials for sustainable polymers. Biobased furan-2,5-dicarboxylic acid (FDCA), for instance, can be produced by the direct oxidation of HMF or even by multistep catalytic reactions of furfural. ${ }^{16,17}$ In recent years, FDCA has attracted considerable interest as the furan analogue of terephthalic acid. It has therefore been used as a monomer to study sustainable FDCA-based polyesters with excellent gas barrier properties, ${ }^{18}$ e.g., poly(ethylene furanoate) (PEF), ${ }^{19-21}$ poly(propylene furanoate) (PPF), ${ }^{22}$ and poly(butylene furanoate) (PBF). ${ }^{23}$ In addition, FDCA has been utilized as a comonomer to obtain PET-based copolyesters with improved performance. ${ }^{24}$ For instance, FDCA was effective for reducing the crystallization activity of PET, as the FDCA moiety is more rigid and polar. ${ }^{19,25}$ The FDCAmodified PET copolyesters were also reported to have improved gas barrier properties. ${ }^{24}$

Other furan-based dicarboxylic acids have also attracted interest: FDCA isomers, particularly furan-2,4-dicarboxylic acid (2,4-FDCA), have also been studied as potential monomers. Polyesters of 2,4-FDCA are quite distinct in their properties compared to the usual polyesters derived from its 2,5congener. A notable difference is the lack of semicrystalline character in 2,4-FDCA polyesters, among other differences such as improved thermal stability. ${ }^{25,26}$ In copolyesters, the inclusion of a relatively small proportion of the 2,4-FDCA isomer can effectively suppress the crystallization of 2,5-FDCAbased polyesters, particularly PEF. ${ }^{27,28} 2,4$-FDCA has also been studied as a comonomer in PET, where the furan units improved the apparent thermal stability and optical transparency. ${ }^{29}$ Despite the fact that furan monomers are useful when aiming for materials with high glass transition temperature range $\left(T_{\mathrm{g}}\right)$, excellent gas barrier, reduced crystallinity, and high optical transmittance, they lack UV-blocking properties in the range of $320-400 \mathrm{~nm}$, similar to PET. ${ }^{29}$

Pioneering work carried out in our research group, and in a few others, over the past few years has shown that furfural assumes a similar role in the synthesis of $2,2^{\prime}$-bifuran-5,5'dicarboxylic acid (BFDCA), a biobased monomer with two connected furan rings, as HMF does in the production of FDCA. ${ }^{30-34}$ BFDCA, or rather its methyl ester, has been polymerized with ethylene glycol to afford poly(ethylene bifuranoate) (PEBF), an analogue to PET and PEF. ${ }^{32-34}$ Interestingly, $\mathrm{PEBF}$ has a much higher glass transition temperature range than PET or PEF, thanks to its $2,2^{\prime}$-bifuran moieties. Additionally, the oxygen barrier properties of PEBF were improved compared to PET, and, in contrast to PET- or FDCA-based polyesters, strong absorption of UV light could be observed at $300-400 \mathrm{~nm}$. A potential drawback of the $2,2^{\prime}-$ bifuran structure was also studied and discussed, i.e., the degradation of PEBF by oxygen at high temperatures. ${ }^{33}$

In terms of BFDCA-containing copolyesters, little work has been done to date. A series of random copolyesters including poly(butylene furanoate) (PBF) and poly(butylene bifuranoate) (PBBF) was recently described by our group. ${ }^{35}$ There, copolymerization of the furan and bifuran monomers afforded highly transparent polyester films with good UV-blocking coverage imparted by the bifuran monomer. All tested polyesters and copolyesters also showed clearly superior oxygen barrier properties with respect to PET. Additionally, the random copolyesters of PBF and PBBF became significantly more amorphous as the amount of comonomer was increased to $10 \mathrm{~mol} \%$ or more. As PET is an attractive target for modification, we were encouraged to study novel copolyesters that would incorporate the main characteristics of PET with some of the added benefits of PEBF into one polyester. To the best of our knowledge, no study has yet focused on utilizing the bifuran moiety in the modification of PET, though a patent application that recently became publicly available discussed the modification of conventional polyesters by incorporating the bifuran monomer into its structure. ${ }^{36}$ Notably, poly(ethylene terephthalate-co-bifuranoate) showed promising thermal behavior.

Herein, we report the potential and behavior of BFDCA as a functional monomer in PETBF copolymers based on our independent studies. A series of PETBF copolymers was synthesized (Scheme 1), and the effect of incorporating a small amount of BFDCA $(0-15 \mathrm{~mol} \%)$ into PET was evaluated with unmodified PET as the reference. Thermomechanical performance, UV-vis transmittance, and oxygen barrier properties of PETBF copolymers were then investigated. Based on this study, BFDCA-modified PET copolyesters differ from the FDCA-modified ones by not only enhancing $T_{\mathrm{g}}$ and reducing crystallinity but also adding UV-barrier properties on top of similar gas barrier performance. In other words, copolymerizing PET with small amounts of BFDCA units provided an intrinsic UV-filtering property, improved oxygen barrier properties, and enhancements in thermomechanical properties compared to unmodified PET.

\section{EXPERIMENTAL SECTION}

Materials. Commercially available solvents and reagents were used as received. Dry ethylene glycol (99\%) and 
tetrabutyl titanate (TBT, 99\%) were stored and kept under dry argon. Finely powdered antimony(III) trioxide (99.9\%) was used as the catalyst for polycondensations. Reactions were conducted under argon atmospheres and monitored using thin-layer chromatography (ethyl acetate:hexane 1:1 as an eluent). Dimethyl 2,2'-bifuran-5,5'-dicarboxylate was synthesized according to our previous report. ${ }^{32}$ All NMR measurements were carried out at room temperature. ${ }^{1} \mathrm{H}$ NMR chemical shifts are referenced to residual solvent peaks in $\mathrm{CF}_{3} \mathrm{COOD}, \mathrm{CDCl}_{3}$, and $\left(\mathrm{CD}_{3}\right)_{2} \mathrm{SO}$ at $11.50,7.27$, and 2.50 ppm, respectively. ${ }^{13} \mathrm{C}$ NMR shifts were referenced to the trifluoromethyl carbon (116.60 ppm, $\left.\mathrm{CF}_{3} \mathrm{COOD}\right)$ in trifluoroacetic acid and to the methyl carbons (39.52 ppm, $\left.\left(\mathrm{CD}_{3}\right)_{2} \mathrm{SO}\right)$ in dimethyl sulfoxide.

Synthesis of Bis(2-hydroxyethyl)-2,2'-bifuran-5,5'-dicarboxylate. A high equivalent ratio of ethylene glycol was used to minimize oligomer formation during the transesterification step. Thus, ethylene glycol (10 equiv, $4.46 \mathrm{~mL}$ ) and TBT $(2 \mathrm{~mol} \%, 54.0 \mathrm{mg})$ were mixed in a $50 \mathrm{~mL}$ roundbottom flask with a magnetic stirring bar. Dimethyl 2,2'bifuran-5,5'-dicarboxylate ( 1 equiv, $2.00 \mathrm{~g}$ ) was added to the reaction flask which was equipped with a distillation bridge and connected to a receiving flask. After protection under argon atmosphere, the reaction temperature was increased to $180^{\circ} \mathrm{C}$. Within $4 \mathrm{~h}$, the starting material had converted into a mixture of mono and bis(2-hydroxyethyl) esters, and after an additional $3 \mathrm{~h}$ reaction, the bifuran diester was obtained. When the reactants melted, the pressure was slightly lowered to $0.6-0.7$ bar to accelerate the removal of the formed methanol. Afterward, the reaction mixture was allowed to cool down and was then diluted with $100 \mathrm{~mL}$ of deionized water. After standing for $12-24 \mathrm{~h}$ at $4{ }^{\circ} \mathrm{C}$, the crude product was filtered off, recrystallized by warm ethanol, diluted with deionized water, and let to settle down for $12 \mathrm{~h}$ at $4{ }^{\circ} \mathrm{C}$. The product (a white crystalline powder, 98\%) was filtrated off, washed with cold deionized water, and dried in vacuum. ${ }^{1} \mathrm{H}$ NMR (400 MHz, $\left.\left(\mathrm{CD}_{3}\right)_{2} \mathrm{SO}, \mathrm{ppm}\right): \delta 7.49(\mathrm{~d}, 2 \mathrm{H}, J=3.7$ $\mathrm{Hz}), 7.18(\mathrm{~d}, 2 \mathrm{H}, J=3.7 \mathrm{~Hz}), 4.95(\mathrm{t}, 2 \mathrm{H}, J=5.7 \mathrm{~Hz}), 4.30(\mathrm{t}$, $4 \mathrm{H}, J=4.8 \mathrm{~Hz}), 3.70(\mathrm{~m}, 4 \mathrm{H}) .{ }^{13} \mathrm{C} \mathrm{NMR}(400 \mathrm{MHz}$, $\left.\left(\mathrm{CD}_{3}\right)_{2} \mathrm{SO}, \mathrm{ppm}\right): \delta 157.5$ (ester carbonyl), 147.0 (furan ring), 143.8 (furan ring), 120.2 (furan ring), 110.2 (furan ring), 66.4 (ester ethyl group), 58.7 (ester ethyl group).

Synthesis of PETBF Copolymers. The polyesters were synthesized by weighing the appropriate amount of diester $(20$ mmol total), e.g., for $\mathrm{PET}_{90} \mathrm{BF}_{10}$, bis(2-hydroxyethyl) terephthalate $(4.8 \mathrm{~g})$ and bis(2-hydroxyethyl)-2,2'-bifuran-5,5'dicarboxylate $(0.62 \mathrm{~g})$, along with antimony(III)trioxide powder $(250 \mathrm{ppm} \mathrm{mol} \%, 1.45 \mathrm{mg}$ ), were placed in a $50 \mathrm{~mL}$ round-bottom flask equipped with an overhead mechanical stirrer with a PTFE stirring rod and connected to a receiving flask via a distillation bridge. Once the system had been purged with vacuum-argon cycles to remove air and moisture, the reactants were allowed to melt at $180{ }^{\circ} \mathrm{C}$. The pressure was then decreased gently to $3 \mathrm{mbar}$, and the temperature was raised slowly to $280{ }^{\circ} \mathrm{C}$. Polymerization was allowed to proceed for $5 \mathrm{~h}$. Then, the polymer was rapidly cooled, and the reaction system was returned to atmospheric pressure. The polyester was dissolved in 1,1,1,3,3,3-hexafluoroisopropanol (HFIP), precipitated by adding methanol to produce off-white, fibrous polyester, which was filtered and washed with methanol, and finally vacuum-dried at $70{ }^{\circ} \mathrm{C}$ for several days. For analysis, the copolyesters were dissolved in a small amount of trifluoroacetic acid $\left(\mathrm{CF}_{3} \mathrm{COOH}\right)$ and $\mathrm{CDCl}_{3}$ for ${ }^{1} \mathrm{H} \mathrm{NMR}$, while ${ }^{13} \mathrm{C}$ NMR was measured in pure $\mathrm{CF}_{3} \mathrm{COOD}$. ${ }^{1} \mathrm{H}$ NMR (400 $\left.\mathrm{MHz}, \mathrm{CDCl}_{3}, \mathrm{ppm}\right): \delta 8.18$ (s, 4H, benzene ring), 7.42 (d, $2 \mathrm{H}, J=3.7 \mathrm{~Hz}$, furan ring), $6.95(\mathrm{~d}, 2 \mathrm{H}, J=3.7 \mathrm{~Hz}$, furan ring), 4.84 (broad s, $4 \mathrm{H}$, ethylene moiety).

Dilute Solution Viscosity. Intrinsic viscosities of methanol-precipitated, vacuum-dried polyesters were determined in a phenol:1,1,2,2-tetrachloroethane (60:40, w/w) mixture using an Ubbelohde viscometer. The Billmeyer equation was used to calculate the intrinsic viscosity at a constant polymer solution concentration $(c)$ of $0.5 \mathrm{~g} / \mathrm{dL}$ and temperature of $30{ }^{\circ} \mathrm{C}$ according to the ASTM D 4603 technique. Intrinsic viscosities were calculated from $[\eta]=\left[0.25 \times\left(\eta_{\mathrm{r}}-1+3 \times \ln \eta_{\mathrm{r}}\right)\right] / c$, where relative viscosities $\eta_{\mathrm{r}}=t / t_{0}$. The elution times of the pure solvent $\operatorname{mix}\left(t_{0}\right)$ and polymer solution $(t)$ were determined from the average of three manual measurements. ${ }^{37}$

Differential Scanning Calorimetry (DSC). A Mettler Toledo DSC (DSC 821e), calibrated with indium standard using the machine calibration method, was used to evaluate the thermal behavior of copolymers, i.e., glass transition, crystallization, and melting temperatures. Experiments were run under inert gas flow $\left(50 \mathrm{~cm}^{3} / \operatorname{min~} \mathrm{N}_{2}\right)$ using heating and cooling cycles at a temperature range of $25-300{ }^{\circ} \mathrm{C}$. The heat flow rate was $10{ }^{\circ} \mathrm{C} / \mathrm{min}$, and the thermal history was deleted by the first heating. Samples (ca. 3-4 mg) were weighed into $40 \mu \mathrm{L}$ aluminum crucibles, which were closed with a pierced lid.

Thermogravimetric Analysis (TGA). A Mettler-Toledo thermogravimetric analyzer (TGA851e), calibrated by indium, aluminum, and zinc standards, was used to determine the copolymer's thermal stability. Methanol-precipitated, vacuumdried polymer samples $(\sim 10 \mathrm{mg})$ were heated from 40 to 700 ${ }^{\circ} \mathrm{C}$ under nitrogen and air atmospheres with a gas flow rate of $40 \mathrm{~cm}^{3} / \mathrm{min}$ and heating rate of $10{ }^{\circ} \mathrm{C} / \mathrm{min}$.

Copolyester Film Processing. A Fontijne hydraulic press (LabEcon 300) was used to obtain melt-pressed polymer films. Copolymer samples $(2-3 \mathrm{~g})$ were placed in between two preheated aluminum plates which were covered with PTFEcoated glass fiber sheets. The film thickness was controlled to ca. $0.2 \mathrm{~mm}$ by using layers of a glass fiber mat as a frame around the polyester samples. Plates were placed in a press with the samples and heated at $260-265{ }^{\circ} \mathrm{C}$ for $3 \mathrm{~min}$ and compressed for $1 \mathrm{~min}$ at $30 \mathrm{kN}$. Plates were removed from the press and quenched immediately in an ice-water bath at $0{ }^{\circ} \mathrm{C}$ for $30 \mathrm{~s}$ and then returned to room temperature. The plates were separated, and polyester film was peeled off to produce melt-pressed films, e.g., $\mathrm{PET}_{90} \mathrm{BF}_{10}$ in Figure $\mathrm{S} 1$. In a second method, the plates were covered in thermally resistant polyimide film to produce highly transparent film pieces used to obtain UV-transmittance data. All of the characterizations were run from the melt-pressed films except viscosity measurements and TGA.

X-ray Diffraction. XRD data were collected at room temperature using a PANalytical X'Pert MPD Pro X-ray diffractometer equipped with a Cu lamp $\left(K_{\alpha 1}=1.5405980\right.$ $\AA)$, at a scanning rate of $0.0213^{\circ} / \mathrm{min}$ and in the $(2 \theta)$ range of $5-38^{\circ}$. Measurements were obtained using melt-pressed polyesters films as-received and after annealing at $155^{\circ} \mathrm{C}$ for $1 \mathrm{~h}$.

Tensile Testing. Tensile testing (Instron 5544, USA) was performed using a gauge length of $30 \mathrm{~mm}$ and cross-head speed of $5 \mathrm{~mm} / \mathrm{min}$. Rectangle-shaped specimens of meltpressed polyester films with $5 \mathrm{~mm}$ width, $60 \mathrm{~mm}$ length, and thicknesses of less than $0.25 \mathrm{~mm}$ were stored at dry ambient 
conditions at room temperature for 14 days before the uniaxial tensile tests and a further $48 \mathrm{~h}$ under standard conditions (23 $\left.{ }^{\circ} \mathrm{C}, 50 \% \mathrm{RH}\right)$ prior to the testing.

Dynamic Mechanical Analysis (DMA). A Q800 Dynamic Mechanical analyzer (TA Instruments), calibrated by polycarbonate standard samples, was used to evaluate the thermomechanical properties of the polyesters from rectangular melt-pressed film pieces $5 \mathrm{~mm}$ wide. DMA-controlled strain mode was used to determine storage modulus $E^{\prime}$, loss modulus $E^{\prime \prime}$, and loss tangent $\tan \delta$ values at constant frequency of $1 \mathrm{~Hz}$ in a temperature range $30-200{ }^{\circ} \mathrm{C}$, with a heating rate of $3{ }^{\circ} \mathrm{C} / \mathrm{min}$.

Oxygen Permeability. MOCON OX-TRAN 2/2 was used to determine the oxygen transmission rate (OTR) from the melt-pressed films at room temperature $\left(23^{\circ} \mathrm{C}\right)$ and $1 \mathrm{~atm}$ pressure at a relative humidity of $50 \%$. The specimen exposure area was $5 \mathrm{~cm}^{2}$. OTR values were measured twice from duplicate samples of melt-pressed films with thicknesses of 0.2 $\pm 0.05 \mathrm{~mm}$. The oxygen permeability coefficient (OPC) of tested copolymer films was calculated by the equation [OPC = OTR $\cdot l / \Delta P$ ] from the film thickness $(l)$ and oxygen partial pressure difference across the two film sides $(\Delta P) .{ }^{38}$ The barrier improvement factor (BIF) was calculated by dividing the PET permeability coefficient by the coefficient of the copolyester.

UV-Vis. UV-vis transmission spectra of transparent meltpressed films were measured using an UV-vis spectrophotometer (Shimadzu 1800) within the wavelength range 200$800 \mathrm{~nm}$. Thin rectangle-shaped pieces $(4 \mathrm{~cm} \times 1 \mathrm{~cm})$ were cut from the films with thicknesses of less than $0.25 \mathrm{~mm}$ to evaluate the UV-blocking behavior of the PETBF copolymers.

\section{RESULTS AND DISCUSSION}

Syntheses. Bis(2-hydroxyethyl) terephthalate can be obtained with high purity and yield by the transesterification of dimethyl terephthalate with ethylene glycol in the presence of a metal catalyst or potentially in a more sustainable manner from the glycolysis of PET waste. ${ }^{39,40}$ In a similar procedure, bis(2-hydroxyethyl)-2,2' -bifuran-5,5'-dicarboxylate was produced by the transesterification of dimethyl 2,2'-bifuran-5,5' dicarboxylate with ethylene glycol at $180{ }^{\circ} \mathrm{C}$ using a titanium catalyst $(2 \mathrm{~mol} \%)$. Despite the yellow discoloration associated with the use of titanium catalysts at high temperatures, the transesterified product was obtained as a white crystalline solid. Random, high molecular weight PETBF copolyesters (Scheme 1) were synthesized similarly to the typical two-step melt polycondensation method. However, the long transesterification step with the exchange of EG and removal of methanol (or water) required before the melt polycondensation was not necessary with the employed terephthalate and bifuranoate 2hydroxyethyl esters: The attack of one 2-hydroxyethyl end group to the ester group of another monomer, with the displacement of ethylene glycol, is expected to take place similarly with both the bifuranote and terephthalate monomers. Thus, the melt-state reaction of the two 2-hydroxyethyl monomers under $3 \mathrm{mbar}$ pressure for $5 \mathrm{~h}$ at $280{ }^{\circ} \mathrm{C}$ in the presence of antimony(III)trioxide catalyst $(250 \mathrm{ppm} \mathrm{mol} \mathrm{\% )}$ afforded high molecular weight polyesters with the removal of ethylene glycol.

Antimony trioxide is one of the most commonly used catalysts in PET manufacture, which is usually used because of its good final appearance. However, despite the use of an antimony-based catalyst and pure white monomers, the resultant melt-pressed films were slightly yellow in appearance (Figure S1). A possible explanation is the sensitivity of bifuran compounds toward oxidation at high temperatures, ${ }^{33}$ e.g., during melt-pressing. It might be avoided by using rigorous inert gas atmospheres during all processing steps, but in the case of our melt-pressing procedure, some air will always be able to contact the polymer melt as it is being processed into a film. In addition, small amounts of air will tend to slowly leak into the polycondensation apparatus during the vacuum step. At the same time, it is recognized that in the literature, the mentioned yellowish color in the prepared furan-based polymers may also stem from minor monomer impurities, decarboxylation, or other side reactions which increase with the furan moiety concentration. Used catalysts may also have an effect. ${ }^{41,42}$

Structure Characterization. Structures of the bifuran diester monomer and PETBF copolymers were confirmed by ${ }^{1} \mathrm{H}$ and ${ }^{13} \mathrm{C}$ NMR measurements (Figures S2-S13). The assignment of the ${ }^{1} \mathrm{H}$ NMR spectra of PETBF copolymers is shown in Figure 1. The four aromatic protons of the phenyl

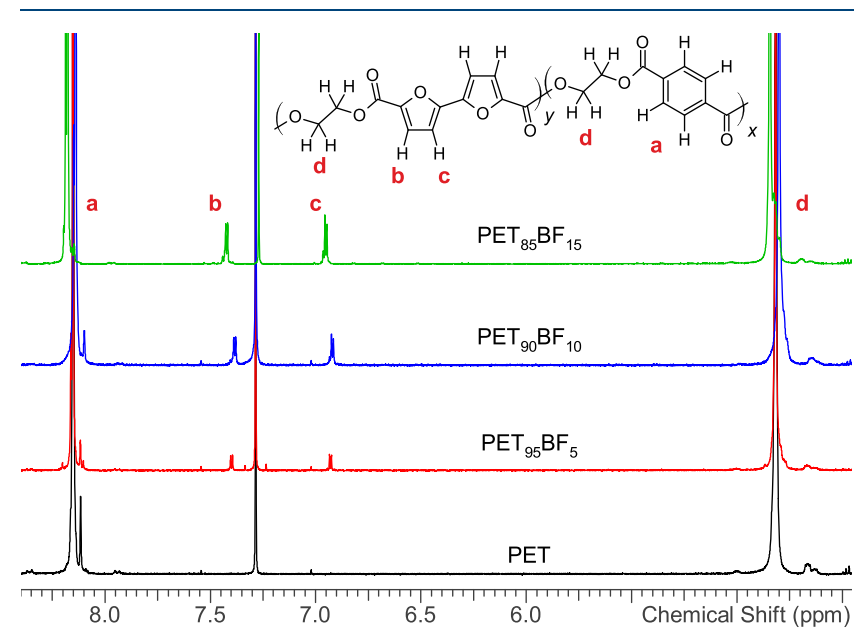

Figure 1. ${ }^{1} \mathrm{H}$ NMR spectra of PETBF copolymers measured in $\mathrm{CDCl}_{3}$ with the relevant peaks assigned to the repeating unit.

ring (a) appear as a singlet at $8.18 \mathrm{ppm}$, while the furan ring protons appear close to the chloroform solvent peak as two doublets (b and c) at 7.42 and $6.95 \mathrm{ppm}$, respectively. The ethylene moiety peak $(\mathrm{d})$ is visible at $4.67 \mathrm{ppm}$. Integration of peaks $b$ and $c$ was used to characterize the content of the bifuran moieties by comparing with the integration of peaks a and $\mathrm{d}$. The calculated compositions of PETBF copolyesters are presented in Table 1. The observed ratios of terephthalate and bifuranoate moieties were close to the feed ratios used, which

Table 1. Composition, Yield, Intrinsic Viscosity, and Biocarbon Content Percent of PET and PETBF Copolymers

\begin{tabular}{lllccc} 
& \multicolumn{2}{c}{ unit ratio $(\mathrm{mol} \%)$} & & & \\
\cline { 2 - 3 } polymer & feed & copolymer & $\begin{array}{c}\text { yield } \\
(\%)\end{array}$ & $\begin{array}{c}{[\eta]} \\
(\mathrm{dL} / \mathrm{g})\end{array}$ & $\begin{array}{c}\text { expected biocarbon } \\
\text { content }(\%)^{a}\end{array}$ \\
\hline PET & 0 & $100: 0$ & 98 & 0.695 & 20 \\
$\mathrm{PET}_{95} \mathrm{BF}_{5}$ & $95: 5$ & $96.1: 3.9$ & 91 & 0.847 & 24.8 \\
$\mathrm{PET}_{90} \mathrm{BF}_{10}$ & $90: 10$ & $91.1: 8.9$ & 94 & 0.723 & 29.4 \\
$\mathrm{PET}_{85} \mathrm{BF}_{15}$ & $85: 15$ & $86.2: 13.8$ & 93 & 0.794 & 34.0
\end{tabular}

${ }^{a}$ Based on feed ratios. 

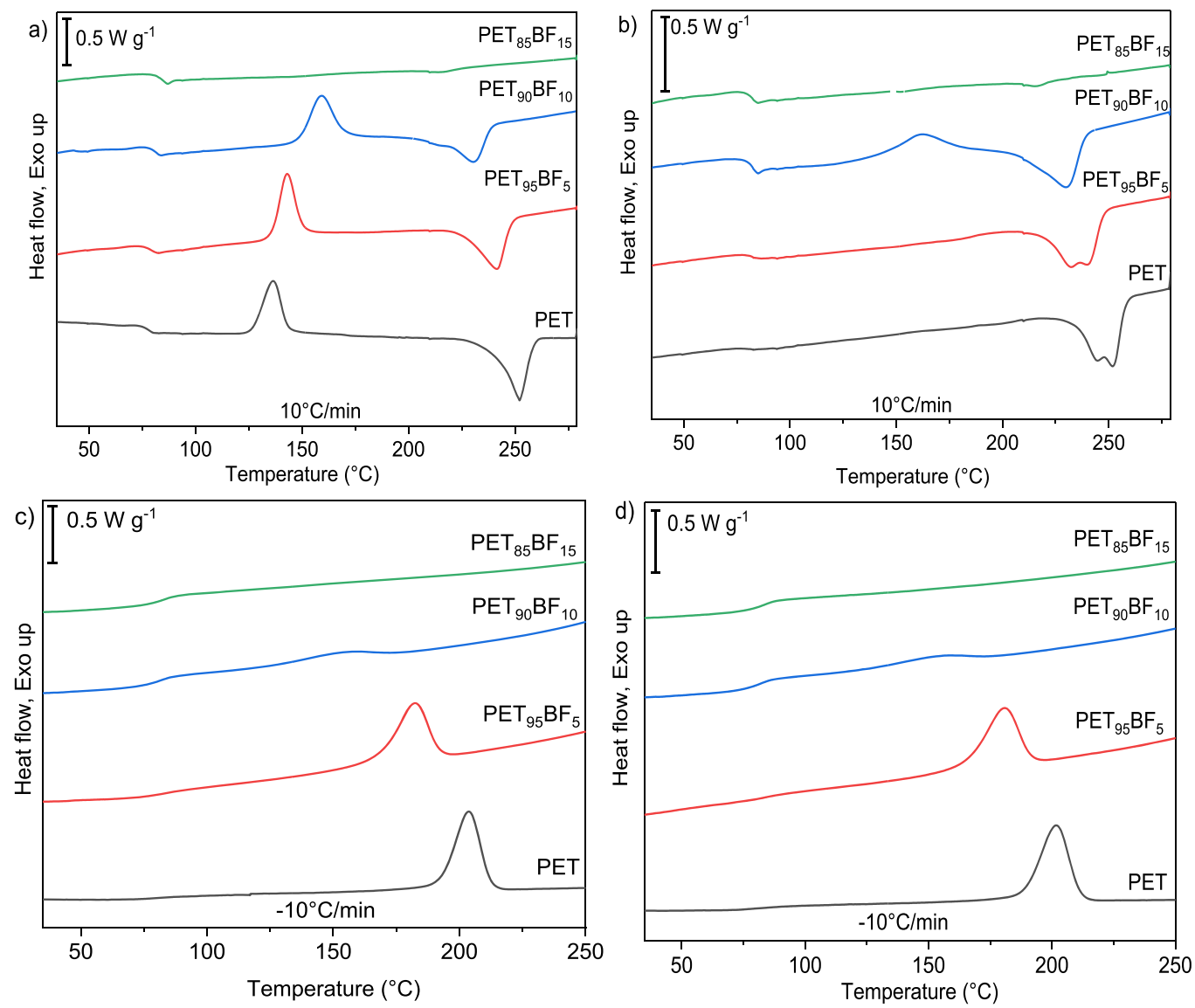

Figure 2. DSC curves of PETBF polyesters: first (a) and second (b) heating cycles and first (c) and second (d) cooling cycles.

indicates successful synthesis of PETBF copolymers within the desired range. The desired intrinsic viscosity of PET is dependent on its application and can be classified into different grades; e.g., it could be $0.40-0.70 \mathrm{dL} / \mathrm{g}$ for fiber grade, $0.78-$ $0.85 \mathrm{dL} / \mathrm{g}$ for bottle grade, and $0.70-1.00 \mathrm{dL} / \mathrm{g}$ for film grade, while for engineering plastic grade it can be $1-2 \mathrm{dL} / \mathrm{g}^{2}$ Intrinsic viscosities of the synthesized PETBF copolyesters were measured to be in the range of $0.72-0.85(\mathrm{dL} / \mathrm{g})$, which indicates that the prepared copolymers have relatively high molecular weights. It is important to notice that the expected biocarbon content of copolyester increases with the increasing BFDCA content (Table 1 and eq S1). For example, over onethird of the carbon of $\mathrm{PET}_{85} \mathrm{BF}_{15}$ is biobased, compared to PET with a maximum of $20 \%$ biobased carbon when ethylene glycol is derived from biomass.

Thermal Properties. Thermal behaviors of PET and PETBF copolymers were evaluated by DSC (Table S1, Figure 2). As described in the literature, both PEF and PEBF have a higher $T_{\mathrm{g}}$ than PET despite their lower or similar melting points. ${ }^{32}-34,43$ Thus, the increased glass transition range and lower melting temperature were expected as a result of incorporating BFDCA into PET. Obvious endothermic and exothermic peaks derived from melting and crystallization, respectively, were observed in the first heating scan (Figure 2a) for all semicrystalline copolymers except $\mathrm{PET}_{85} \mathrm{BF}_{15}$. The lack of a distinctive melting peak indicates that this copolymer already has a greater amorphous character compared to the other polyesters tested. Notable are also the sharp melting peaks of PET and $\mathrm{PET}_{95} \mathrm{BF}_{5}$ in the first heating scan, which turn into double peaks in the second scan (Figure 2b). Such double or multiple melting behavior during DSC heating scans has been reported in many semicrystalline polymers. Multiple melting peaks occur as a result of annealing effects, the presence of different crystal morphologies, recrystallization effects, remelting processes during the subsequent heating, physical aging, and/or relaxation of the rigid amorphous portion. ${ }^{43-45}$ The crystallization behavior at the selected conditions is also worthy of note: The polyesters, apart from $\mathrm{PET}_{85} \mathrm{BF}_{15}$, crystallize with a prominent exotherm during the first heating run, indicating initially an amorphous state. Upon cooling, PET and $\mathrm{PET}_{95} \mathrm{BF}_{5}$ crystallize from the melt, which is not the case with $\mathrm{PET}_{90} \mathrm{BF}_{10}$ and $\mathrm{PET}_{85} \mathrm{BF}_{15}$ where exotherms cannot be observed. However, $\mathrm{PET}_{90} \mathrm{BF}_{10}$ once again crystallizes starting from the glassy state after the first cooling run. The crystallization behavior of $\mathrm{PET}_{90} \mathrm{BF}_{10}$ is similar to that of PEFT and PEIT with 6 and $10 \mathrm{~mol} \%$ of FDCA and isophthalic acid, respectively, as the comonomer. ${ }^{24}$ It is also similar to the inhibition of crystallization and formation of more amorphous copolymers as a result of incorporating either 2,4-FDCA into 2,5-PEF, 27 2,5-FDCA into PET, ${ }^{24,46}$ or BFDCA into $\mathrm{PBF}^{35}$ at a molar ratio of more than $10 \mathrm{~mol} \%$. However, in the case of PETBF copolymers, the BFDCA comonomer enhances the $T_{\mathrm{g}}$ more than FDCA in the PEFT copolyesters, as expected. In conclusion, BFDCA as a comonomer with a content of $10 \mathrm{~mol} \%$ or less effectively enhances the thermal behavior of PET and hinders its crystallinity without a significant drop in the melting point.

In addition to DSC, the films were also characterized using $\mathrm{XRD}$, which confirmed the amorphous morphology of the melt-pressed films. The X-ray patterns of annealed films 

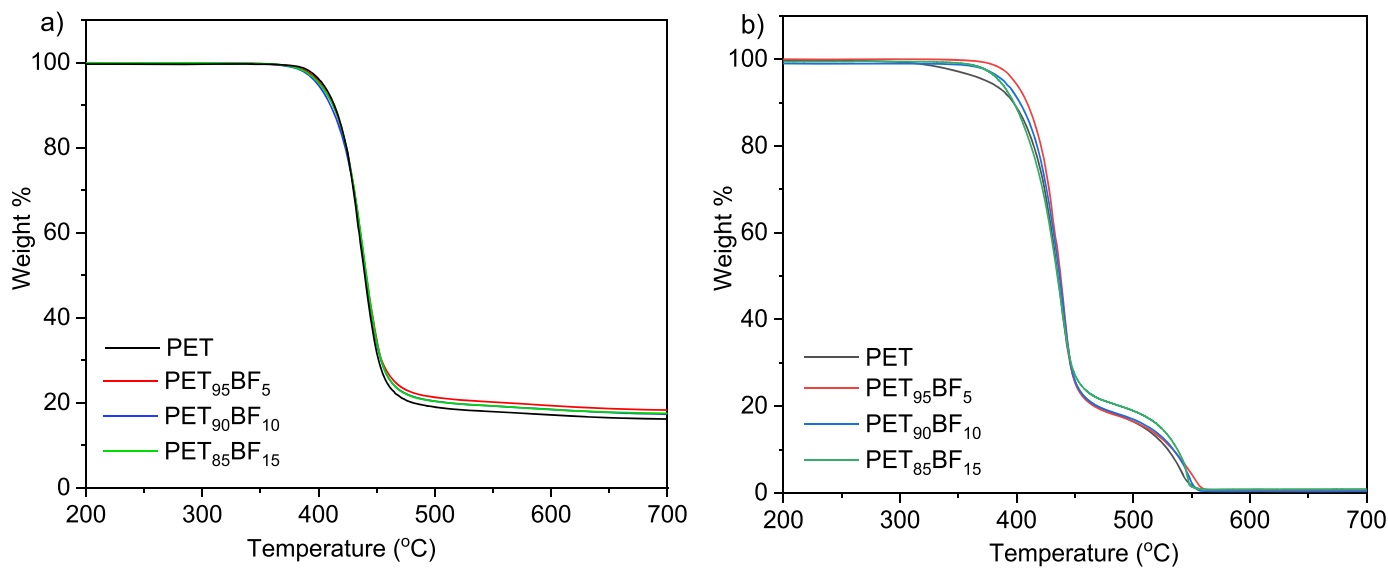

Figure 3. Thermogravimetric decomposition curves of synthesized PET and PETBF copolymers under (a) nitrogen atmosphere and (b) air atmosphere.

(Figure S14) highlight the semicrystalline nature of the copolyesters. Notably, the main diffraction reflections observed in the PET pattern are also present in all of the PETBF copolymers at $(2 \theta) 16.63^{\circ}, 17.45^{\circ}, 21.51^{\circ}, 21.86^{\circ}, 22.66^{\circ}$, $23.04^{\circ}, 25.93^{\circ}$, and $32.95^{\circ}$. This similarity in crystal structures could be attributed to the crystallinity disruption; i.e., there are no new reflections appearing.

Thermogravimetric analyses under $\mathrm{N}_{2}$ atmosphere show that the decompositions of the different samples were within a $5{ }^{\circ} \mathrm{C}$ window (Table S1, Figure 3a). The PET and PETBF copolyesters decomposed in a single step in the range of 399-441 ${ }^{\circ} \mathrm{C}$. The results indicate that the thermal stabilities are largely unaffected and high enough to allow the melts to be processed in a similar fashion. The residual sample masses of BFDCA-containing polymers at $700{ }^{\circ} \mathrm{C}$ (i.e., char yield) were observed to be higher than the residual mass of PET, again consistent with the earlier results related to BFDCA-based polyesters. $^{32,35}$ TGA data obtained under air atmosphere (Table S1, Figure 3b) show no significant weight loss to up to $380{ }^{\circ} \mathrm{C}$ for PETBF copolyesters, whereas PET showed faster decomposition with the weight loss increasing significantly past $330{ }^{\circ} \mathrm{C}$. No final residue is left by the end of the TGA runs because of the oxidative conditions. In contrast, the major decomposition steps appear closely similar to the ones measured under nitrogen. The smaller second step, indicating decomposition (burning) of the char residue from the first step, is almost complete at $550{ }^{\circ} \mathrm{C}$ in all samples.

Mechanical Properties. The applications of polymeric materials are directly linked to their mechanical properties. Tensile properties including Young's modulus $\left(E_{\mathrm{t}}\right)$, maximum tensile stress $\left(\sigma_{\mathrm{m}}\right)$, and elongation at the break $\left(\varepsilon_{\mathrm{b}}\right)$ are important mechanical properties to be evaluated, especially for polymers used as film packaging. The mechanical properties of the synthesized PET and PETBF polyesters melt-pressed films were investigated with tensile tests, and the observed results are shown in Table 2 and Figure S15. As expected, the Young's modulus increased because of the increased stiffness of the bifuran comonomer. The maximum tensile stresses, on the other hand, appeared slightly lower in the PETBF copolyesters, although still within close range of PET. The high elongation at the break value measured for PET was only matched by $\mathrm{PET}_{90} \mathrm{BF}_{10}$, but $\mathrm{PET}_{95} \mathrm{BF}_{5}$ and $\mathrm{PET}_{85} \mathrm{BF}_{15}$ still had relatively high elongations at ca. $300-400 \%$. It is of course expected that small differences occurred in crystallinities, morphologies, and
Table 2. Measured Tensile Properties of the Polyesters ${ }^{a}$

\begin{tabular}{lclcl}
\multicolumn{1}{c}{ sample } & $E_{\mathrm{t}}(\mathrm{GPa})$ & $\sigma_{\mathrm{m}}(\mathrm{MPa})$ & $\varepsilon_{\mathrm{b}}(\%)$ & \multicolumn{1}{c}{ reference } \\
PET & $1522 \pm 70$ & $58 \pm 10$ & $600 \pm 40$ & current study \\
$\mathrm{PET}_{95} \mathrm{BF}_{5}$ & $1700 \pm 50$ & $48 \pm 2.5$ & $270 \pm 30$ & $"$ \\
$\mathrm{PET}_{90} \mathrm{BF}_{10}$ & $1822 \pm 30$ & $53 \pm 3.7$ & $600 \pm 45$ & $"$ \\
$\mathrm{PET}_{85} \mathrm{BF}_{15}$ & $2015 \pm 100$ & $46 \pm 2$ & $395 \pm 25$ & $"$ \\
$\mathrm{PEBF}$ & $2453 \pm 140$ & $12 \pm 1$ & $0.5 \pm 0.05$ & ref 32 \\
PEBF & $3200 \pm 100$ & $102 \pm 4$ & $20 \pm 10$ & ref 33
\end{tabular}

${ }^{a}$ At least five specimens were evaluated for each polyester. $E_{\mathrm{t}}=$ tensile modulus. $\sigma_{\mathrm{m}}=$ maximum tensile stress. $\varepsilon_{\mathrm{b}}=$ elongation at break.

molecular weights between the different samples, which may cause differences in mechanical properties of polyesters. Considering this, the deviations in the maximum tensile stresses and elongations between PET and the copolyesters can be said to be in a relatively good range, and therefore, the materials seem to provide similar performance. ${ }^{47}$

The viscoelastic response and the damping characteristics of PETBF copolymers were determined from the storage modulus $E^{\prime}$, loss modulus $E^{\prime \prime}$, and $\tan \delta$. The $T_{\mathrm{g}}$ can be additionally evaluated from the peak of the $\tan \delta$ curve or from the peak of the $E^{\prime \prime}$ curve (Table S2, Figure S16). ${ }^{48,49}$ The $T_{\mathrm{g}}$ values obtained from DMA $E^{\prime \prime}$ and $\tan \delta$ curves showed the same general trend of increasing $T_{\mathrm{g}}$ with higher bifuran content. Another notable feature in the DMA is the appearance of cold crystallization in all samples; i.e., because of the slow heating rate even $\mathrm{PET}_{85} \mathrm{BF}_{15}$ shows a sudden increase in $E^{\prime}$ after about $165{ }^{\circ} \mathrm{C}$. After $T_{\mathrm{g}}, \mathrm{PET}_{95} \mathrm{BF}_{5}, \mathrm{PET}_{90} \mathrm{BF}_{10}$, and $\mathrm{PET}_{85} \mathrm{BF}_{15}$ reached $E^{\prime}$ peak values at ca. 155,170 , and $185^{\circ} \mathrm{C}$, respectively. It is clear that the cold crystallization is pushed to much higher temperatures as the bifuran content increases, and, at the same time, the apparent plateau of $E^{\prime}$ appears to settle to lower values. This suggests that much lower crystallinity is attained under the same conditions, with more difficulty. Thus, cold crystallization allows the PET sample to return to an $E^{\prime}$ that is about a magnitude lower than the room temperature value, whereas the $\mathrm{PET}_{85} \mathrm{BF}_{15}$ sample appears to plateau to an $E^{\prime}$ of about two magnitudes lower.

Oxygen Permeability Performance. Permeability depends on multiple factors such as the size, shape, and polarity of the diffusing particle and on properties of the sample, e.g., crystallinity and polymer chain mobility. ${ }^{50}$ One of the attractive properties of PET is its relatively good gas barrier 
performance, though new biobased furan polyesters have quickly proven superior. ${ }^{6}$ As mentioned in the Introduction, both FDCA- and BFDCA-based polyesters and their copolyesters can be very effective at achieving enhanced oxygen barrier properties. Previous studies have described correlations between the enhanced gas barrier properties and the chemical and morphological characteristics of furan-based polyesters. Notably, the 2,5-disubstituted furan moiety, as well as the 2,2'-bifuran unit, have nonlinear 2,5-disubstituted structures, where the hindered ring-flipping motions can be invoked to explain the significant reductions in oxygen permeabilities. ${ }^{19,25,28}$ Previous results have shown that FDCA can also be utilized as a comonomer in order to obtain PET copolyesters with superior oxygen barrier performance. ${ }^{24}$ Thus, it was expected that our PETBF copolyesters would similarly have enhanced oxygen barrier properties. The barrier properties of the new PETBF polyesters are compared in Table 3 and Figure 4. Results were also compared with the reference PET samples.

Table 3. Barrier Improvement Factor (BIF) of Synthesized PET and Copolymer PETBF Compared with Other Reported Polymers

\begin{tabular}{llll} 
polymer & BIF & \multicolumn{1}{c}{ conditions } & \multicolumn{1}{c}{ reference } \\
PET & 1 & $23{ }^{\circ} \mathrm{C}, 1 \mathrm{~atm}, 50 \% \mathrm{RH}$ & \multicolumn{2}{c}{ current study } \\
$\mathrm{PET}_{95} \mathrm{BF}_{5}$ & 1.1 & $"$ & $"$ \\
$\mathrm{PET}_{90} \mathrm{BF}_{10}$ & 1.18 & $"$ & $"$ \\
$\mathrm{PET}_{85} \mathrm{BF}_{15}$ & 1.26 & $"$ & " \\
$\mathrm{PEBF}$ & 2.4 & $23{ }^{\circ} \mathrm{C}, 1 \mathrm{~atm}, 0 \% \mathrm{RH}$ & ref 32 \\
$\mathrm{PEFT}_{6}$ & 1.18 & $30{ }^{\circ} \mathrm{C}, 1 \mathrm{~atm}, 50 \% \mathrm{RH}$ & ref 24 \\
$\mathrm{PEFT}_{20}$ & 1.76 & $"$ & $"$ \\
$\mathrm{PEIT}_{6}$ & 1.05 & $"$ & $"$ \\
$\mathrm{PEIT}_{20}$ & 1.34 & $"$ & $"$ \\
\hline
\end{tabular}

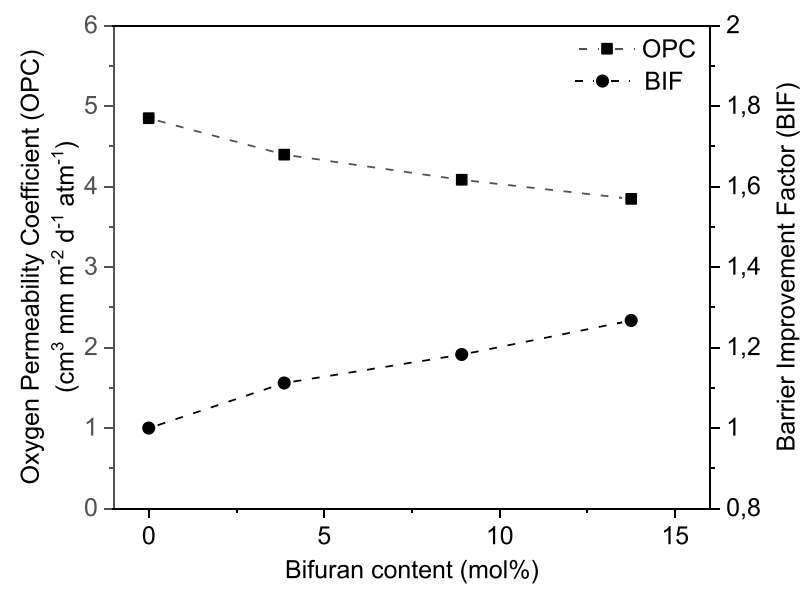

Figure 4. Variation in oxygen permeability coefficients (OPC) and barrier improvement factor (BIF) of PETBF polyesters as a function of bifuran content (mol \%).

The BIF values for the new copolyesters were close to the FDCA-modified PET and isophthalic acid-modified PET (PEIT) copolyesters, e.g., $\mathrm{PET}_{95} \mathrm{BF}_{5}, \mathrm{PEFT}_{6}$, and $\mathrm{PEIT}_{6}$, though the current measurements are carried out under slightly different conditions. ${ }^{24}$ Interestingly, we observed that the permeability coefficients of all samples displayed a noticeable lowering upon further storage at ambient (below $25{ }^{\circ} \mathrm{C}$ ) conditions. As highly amorphous films with very little crystallinity were prepared by quenching the samples into ice-water after melting and pressing, it may be that physical aging contributed to these changes. After all, even far below the $T_{\mathrm{g}}$ of the polymers, it is expected that the slow structural relaxation of the polymer continues within the amorphous parts, and resulting changes in, e.g., free volume and chain packing are known to affect properties such as gas permeability, density, brittleness, tensile strength, and glass transition. ${ }^{1-54}$ Therefore, OTR and BIF values were calculated from the average of two measurements from duplicate samples of melt-pressed films. In conclusion, the results demonstrate that enhanced oxygen barrier performance is observed with increasing bifuran content and that even at a low bifuran content, there is a measurable improvement. The effect appears similar to the effect of isophthalic and 2,5furandicarboxylic acids and offers new prospects for real-world packaging applications, where improved barrier properties are desired for PET.

UV-Blocking Properties. As discussed in previous studies concerning the incorporation of $2,2^{\prime}$-bifuran units into the chemical structures of polyesters, the UV-absorbing properties make BFDCA an interesting multifunctional monomer, which provides an intrinsic UV-barrier property for the resulting polymers. BFDCA provided noticeable UV-shielding properties even at relatively low concentrations of $1-10 \mathrm{~mol} \%$ when used as a minor component in random PBF-co-PBBF polyesters, where PBF lacks significant absorbance of longwavelength UV light. ${ }^{35}$ Unlike the FDCA-modified PET, the prepared PETBF copolyester films showed strong UV absorptions over the whole UV range of 200-400 nm (Table 4, Figure 5). Depending on the content, the

Table 4. Transmittance Values at Different Wavelengths and Maximum UV-Blocking Wavelength of the Polyester Films (Max. $0.25 \mathrm{~mm}$ Thickness) ${ }^{a}$

\begin{tabular}{lllllll}
\multicolumn{1}{c}{ sample } & $\begin{array}{l}T_{350} \\
(\%)\end{array}$ & $\begin{array}{l}T_{380} \\
(\%)\end{array}$ & $\begin{array}{l}T_{400} \\
(\%)\end{array}$ & $\begin{array}{l}T_{450} \\
(\%)\end{array}$ & $\begin{array}{c}\text { cutoff } \\
(\mathrm{nm})\end{array}$ & reference \\
PET & 55.5 & 70.9 & 74.1 & 78.5 & 315 & $\begin{array}{c}\text { current } \\
\text { study }\end{array}$ \\
& & & & & \multicolumn{2}{c}{} \\
$\mathrm{PET}_{95} \mathrm{BF}_{5}$ & 0 & 50 & 64.9 & 73.2 & 362 & $"$ \\
$\mathrm{PET}_{90} \mathrm{BF}_{10}$ & 0.1 & 0.9 & 28.1 & 66.8 & 390 & $"$ \\
$\mathrm{PET}_{85} \mathrm{BF}_{15}$ & 0.1 & 0.8 & 21.6 & 58.5 & 392 & $"$ \\
$\mathrm{PEBF}$ & 0 & 0.1 & 9.4 & 64.3 & 394 & ref 32
\end{tabular}

${ }^{a} T_{350}=$ transmittance at $350 \mathrm{~nm} . T_{380}=$ transmittance at $380 \mathrm{~nm} . T_{400}$ $=$ transmittance at $400 \mathrm{~nm} . T_{450}=$ transmittance at $450 \mathrm{~nm}$.

incorporation of bifuran moieties into PET copolyester films prevented the transmission of most of the UV-A spectrum $(400-320 \mathrm{~nm})$ and $100 \%$ of the UV-B and UV-C spectra at 320-275 and 275-200 $\mathrm{nm}$, respectively. This excellent UVblocking performance can be attributed to the highly conjugated molecular structure of the BFDCA unit. On the other hand, the transmittance is one of the most important indicators to evaluate the transparency of polymer films. Unlike $\operatorname{lignin}^{10-14}$ or $\alpha$-truxillic acid ${ }^{15}$ modified polyesters, PETBF copolyesters showed high transmittance values in the visible range (up to $78 \%$ ). Interestingly, very efficient UV blocking with high transparency in the visible range was reported utilizing biobased thiazolopyridine dicarboxylic acid (TPDA) as an UV-absorbing unit recently. ${ }^{55}$ However, the compounds were used as additives since TPDA-based oligomers were mechanically blended in poly(ethylene terephthalate-co-1,4- 


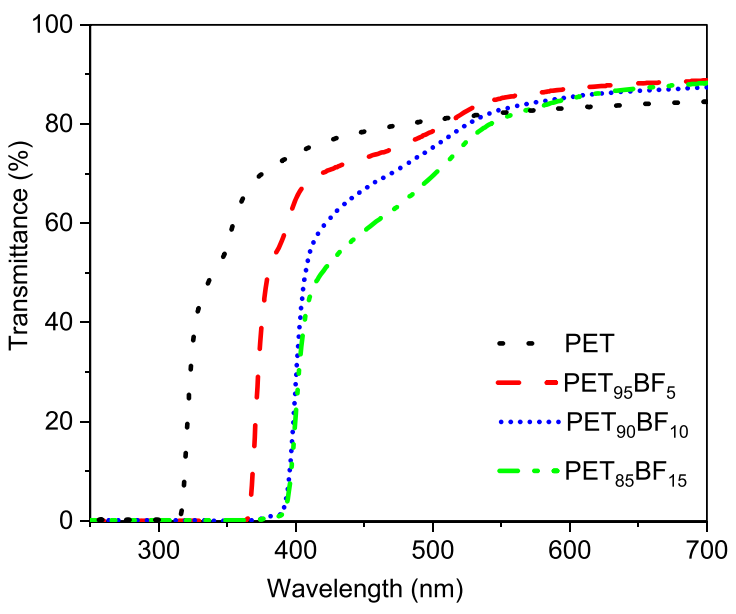

Figure 5. UV-vis transmittance curves of melt-pressed polymer films, max $0.25 \mathrm{~mm}$ thickness.

cyclohexylenedimethylene terephthalate) matrices. As discussed in the Introduction, negative impacts on the environment and human health are related to the utilization of additives. Therefore, PET modification by copolymerization with the UV-blocking moiety might reduce the risk of migration from the polymer bulk into the medium in contact with the polymer and food contamination. In summary, BFDCA-modified PET provided superior UV-blocking performance, which is an interesting additional enhancement alongside the oxygen barrier improvements, even at low bifuran contents without severe effects in polymer transparence and less discoloration.

\section{CONCLUSIONS}

This work highlighted the modification of PET by a biobased multifunctional furfural-derived monomer. Poly(ethylene terephthalate-co-bifuranoate)s were successfully synthesized by utilizing the monomeric 2-hydroxyethyl esters of terephthalic and 2,2'-bifuran-5,5'-dicarboxylic acids. It was found that the glass transition range was slightly enhanced by the presence of the bifuran moieties, along with improvements in the tensile moduli and, importantly, the oxygen barrier properties with respect to PET. The modified properties were achieved while still preserving the semicrystalline nature of the bifuranmodified PET polyesters. As an additional benefit, the modification also added highly effective intrinsic UV barrier properties on top of the gas barrier enhancements, which is a departure from comonomers such as 2,5-furandicarboxylic acid or isophthalic acid. Thus, BFDCA can be identified as a multifunctional comonomer for PET modification, preferred at a molar ratio equal to or less than $10 \mathrm{~mol} \%$, where it reduces crystallinity and depresses the melting temperature while slightly increasing the $T_{\mathrm{g}}$, improving oxygen barrier properties, and blocking the transmission of UV light. The nature of these improvements makes novel PETBF copolyesters a highly promising material choice, especially for demanding packaging applications.

\section{ASSOCIATED CONTENT}

\section{(s) Supporting Information}

The Supporting Information is available free of charge at https://pubs.acs.org/doi/10.1021/acs.iecr.1c00629.
Digital image of copolymer $\mathrm{PET}_{90} \mathrm{BF}_{10}$ melt-pressed film (Figure S1); ${ }^{1} \mathrm{H}$ and ${ }^{13} \mathrm{C} \mathrm{NMR}$ spectra of bis $(2$ hydroxyethyl)-2,2'-bifuran-5,5'-dicarboxylate (Figures S2-S4);; ${ }^{1} \mathrm{H}$ and ${ }^{13} \mathrm{C}$ NMR spectra for synthesized polyesters (Figures S5-S13); DSC and TGA characterization (Table S1); XRD diffractograms of polyester films (Figure S14); the most representative stress-strain curves (Figure S15); DMA data for synthesized polyesters (Figure S16, Table S2) (PDF)

\section{AUTHOR INFORMATION}

\section{Corresponding Author}

Juha P. Heiskanen - Research Unit of Sustainable Chemistry, University of Oulu, FI-90014 Oulu, Finland; O orcid.org/ 0000-0002-1884-1583; Email: juha.heiskanen@oulu.fi

\section{Authors}

Asmaa M. Ahmed - Research Unit of Sustainable Chemistry, University of Oulu, FI-90014 Oulu, Finland; 10 orcid.org/ 0000-0001-8218-2909

Tuomo P. Kainulainen - Research Unit of Sustainable Chemistry, University of Oulu, FI-90014 Oulu, Finland; (1) orcid.org/0000-0001-7027-8209

Complete contact information is available at: https://pubs.acs.org/10.1021/acs.iecr.1c00629

\section{Notes}

The authors declare no competing financial interest.

\section{ACKNOWLEDGMENTS}

The Faculty of Technology (University of Oulu) is thanked for providing financial support. Dr. Tao $\mathrm{Hu}$ is thanked for providing guidance in obtaining the XRD data.

\section{REFERENCES}

(1) Ellen MacArthur Foundation. The New Plastics Economy: Rethinking the Future of Plastics \& Catalysing Action; Ellen MacArthur Foundation, 2017. https://www.ellenmacarthurfoundation.org/ publications/the-new-plastics-economy-rethinking-the-future-ofplastics-catalysing-action.

(2) Ji, L. N. Study on Preparation Process and Properties of Polyethylene Terephthalate (PET). Appl. Mech. Mater. 2013, 312, 406-410.

(3) Pang, J.; Zheng, M.; Sun, R.; Wang, A.; Wang, X.; Zhang, T. Synthesis of Ethylene Glycol and Terephthalic Acid from Biomass for Producing PET. Green Chem. 2016, 18 (2), 342-359.

(4) Tachibana, Y.; Kimura, S.; Kasuya, K. I. Synthesis and Verification of Biobased Terephthalic Acid from Furfural. Sci. Rep. 2015, 5, 1-5.

(5) Lin, Y.; Bilotti, E.; Bastiaansen, C. W. M.; Peijs, T. Transparent Semi-Crystalline Polymeric Materials and Their Nanocomposites: A Review. Polym. Eng. Sci. 2020, 60 (10), 2351-2376.

(6) Terzopoulou, Z.; Papadopoulos, L.; Zamboulis, A.; Papageorgiou, D. G.; Papageorgiou, G. Z.; Bikiaris, D. N. Tuning the Properties of Furandicarboxylic Acid-Based Polyesters with Copolymerization: A Review. Polymers 2020, 12 (6), 1209.

(7) Gohil, R. M. Properties and Strain Hardening Character of Polyethylene Terephthalate Containing Isosorbide Ramesh. Polym. Eng. Sci. 2009, 49 (3), 544-553.

(8) Coughlin, G.; Schambony, S. New UV Absorber for Pet Packaging: Better Protection with Less Discoloration. J. Plast. Film Sheeting 2008, 24 (3-4), 227-238.

(9) Hahladakis, J. N.; Velis, C. A.; Weber, R.; Iacovidou, E.; Purnell, P. An Overview of Chemical Additives Present in Plastics: Migration, 
Release, Fate and Environmental Impact during Their Use, Disposal and Recycling. J. Hazard. Mater. 2018, 344, 179-199.

(10) Sadeghifar, H.; Ragauskas, A. Lignin as a UV Light Blocker-A Review. Polymers 2020, 12 (5), 1134.

(11) Zhang, X.; Liu, W.; Yang, D.; Qiu, X. Biomimetic Supertough and Strong Biodegradable Polymeric Materials with Improved Thermal Properties and Excellent UV-Blocking Performance. Adv. Funct. Mater. 2019, 29 (4), 1806912.

(12) Kun, D.; Pukánszky, B. Polymer/Lignin Blends: Interactions, Properties, Applications. Eur. Polym. J. 2017, 93, 618-641.

(13) Xing, Q.; Buono, P.; Ruch, D.; Dubois, P.; Wu, L.; Wang, W. J. Biodegradable UV-Blocking Films through Core-Shell Lignin-Melanin Nanoparticles in Poly(Butylene Adipate- Co-Terephthalate). ACS Sustainable Chem. Eng. 2019, 7 (4), 4147-4157.

(14) Xing, Q.; Ruch, D.; Dubois, P.; Wu, L.; Wang, W. J. Biodegradable and High-Performance Poly(Butylene Adipate-CoTerephthalate)-Lignin UV-Blocking Films. ACS Sustainable Chem. Eng. 2017, 5 (11), 10342-10351.

(15) Ding, L.; Liu, L.; Chen, Y. F.; Du, Y.; Guan, S. J.; Bai, Y.; Huang, Y. Modification of Poly(Ethylene Terephthalate) by Copolymerization of Plant-Derived $\alpha$-Truxillic Acid with Excellent Ultraviolet Shielding and Mechanical Properties. Chem. Eng. J. 2019, 374, 1317-1325.

(16) Pan, T.; Deng, J.; Xu, Q.; Zuo, Y.; Guo, Q. X.; Fu, Y. Catalytic Conversion of Furfural into a 2,5-Furandicarboxylic Acid-Based Polyester with Total Carbon Utilization. ChemSusChem 2013, 6 (1), $47-50$.

(17) Zhang, S.; Lan, J.; Chen, Z.; Yin, G.; Li, G. Catalytic Synthesis of 2,5-Furandicarboxylic Acid from Furoic Acid: Transformation from C5 Platform to C6 Derivatives in Biomass Utilizations. ACS Sustainable Chem. Eng. 2017, 5 (10), 9360-9369.

(18) Gopalakrishnan, P.; Narayan-Sarathy, S.; Ghosh, T.; Mahajan, K.; Belgacem, M. N. Synthesis and Characterization of Bio-Based Furanic Polyesters. J. Polym. Res. 2014, 21 (1), 340-349.

(19) Burgess, S. K.; Leisen, J. E.; Kraftschik, B. E.; Mubarak, C. R.; Kriegel, R. M.; Koros, W. J. Chain Mobility, Thermal, and Mechanical Properties of Poly(Ethylene Furanoate) Compared to Poly(Ethylene Terephthalate). Macromolecules 2014, 47 (4), 1383-1391.

(20) Burgess, S. K.; Kriegel, R. M.; Koros, W. J. Carbon Dioxide Sorption and Transport in Amorphous Poly(Ethylene Furanoate). Macromolecules 2015, 48 (7), 2184-2193.

(21) Araujo, C. F.; Nolasco, M. M.; Ribeiro-Claro, P. J. A.; Rudić, S.; Silvestre, A. J. D.; Vaz, P. D.; Sousa, A. F. Inside PEF: Chain Conformation and Dynamics in Crystalline and Amorphous Domains. Macromolecules 2018, 51 (9), 3515-3526.

(22) Vannini, M.; Marchese, P.; Celli, A.; Lorenzetti, C. Fully Biobased Poly(Propylene 2,5-Furandicarboxylate) for Packaging Applications: Excellent Barrier Properties as a Function of Crystallinity. Green Chem. 2015, 17 (8), 4162-4166.

(23) Wang, J.; Liu, X.; Zhu, J.; Jiang, Y. Copolyesters Based on 2,5Furandicarboxylic Acid (FDCA): Effect of 2,2,4,4-Tetramethyl-1,3Cyclobutanediol Units on Their Properties. Polymers 2017, 9 (12), 305.

(24) Sun, L.; Zhang, Y.; Wang, J.; Liu, F.; Jia, Z.; Liu, X.; Zhu, J. 2,5Furandicarboxylic Acid as a Sustainable Alternative to Isophthalic Acid for Synthesis of Amorphous Poly(Ethylene Terephthalate) Copolyester with Enhanced Performance. J. Appl. Polym. Sci. 2019, 136 (11), 47186.

(25) Bourdet, A.; Esposito, A.; Thiyagarajan, S.; Delbreilh, L.; Affouard, F.; Knoop, R. J. I.; Dargent, E. Molecular Mobility in Amorphous Biobased Poly(Ethylene 2,5-Furandicarboxylate) and Poly(Ethylene 2,4-Furandicarboxylate). Macromolecules 2018, 51 (5), 1937-1945.

(26) Nolasco, M. M.; Araujo, C. F.; Thiyagarajan, S.; Rudić, S.; Vaz, P. D.; Silvestre, A. J. D.; Ribeiro-Claro, P. J. A.; Sousa, A. F. Asymmetric Monomer, Amorphous Polymer? Structure-Property Relationships in 2,4-FDCA and 2,4-PEF. Macromolecules 2020, 53 (4), 1380-1387.
(27) Thiyagarajan, S.; Meijlink, M. A.; Bourdet, A.; Vogelzang, W.; Knoop, R. J. I.; Esposito, A.; Dargent, E.; Van Es, D. S.; Van Haveren, J. Synthesis and Thermal Properties of Bio-Based Copolyesters from the Mixtures of 2,5- and 2,4-Furandicarboxylic Acid with Different Diols. ACS Sustainable Chem. Eng. 2019, 7, 18505-18516.

(28) Bourdet, A.; Araujo, S.; Thiyagarajan, S.; Delbreilh, L.; Esposito, A.; Dargent, E. Molecular Mobility in Amorphous Biobased Copolyesters Obtained with 2,5- and 2,4-Furandicarboxylate Acid. Polymer 2021, 213, 123225.

(29) Zaidi, S.; Thiyagarajan, S.; Bougarech, A.; Sebti, F.; Abid, S.; Majdi, A.; Silvestre, A. J. D.; Sousa, A. F. Highly Transparent Films of New Copolyesters Derived from Terephthalic and 2,4-Furandicarboxylic Acids. Polym. Chem. 2019, 10 (39), 5324-5332.

(30) Miyagawa, N.; Ogura, T.; Okano, K.; Matsumoto, T.; Nishino, T.; Mori, A. Preparation of Furan Dimer-Based Biopolyester Showing High Melting Points. Chem. Lett. 2017, 46 (10), 1535-1538.

(31) Miyagawa, N.; Suzuki, T.; Okano, K.; Matsumoto, T.; Nishino, T.; Mori, A. Synthesis of Furan Dimer-Based Polyamides with a High Melting Point. J. Polym. Sci., Part A: Polym. Chem. 2018, 56 (14), $1516-1519$.

(32) Kainulainen, T. P.; Sirviö, J. A.; Sethi, J.; Hukka, T. I.; Heiskanen, J. P. UV-Blocking Synthetic Biopolymer from BiomassBased Bifuran Diester and Ethylene Glycol. Macromolecules 2018, 51 (5), 1822-1829.

(33) Edling, H. E.; Sun, H.; Paschke, E.; Schiraldi, D. A.; Tanko, J. M.; Paradzinsky, M.; Turner, S. R. High Barrier Biosourced Polyester from Dimethyl [2,2'-Bifuran]-5,5'-Dicarboxylate. Polymer 2020, 191, 122258.

(34) Lei, Y.; Zhang, S.; Shen, G.; Zhu, J.; Xue, J.; Chen, Z.; Yin, G. Feasible Synthesis of a Bifuran-Based Monomer for Polymer Synthesis from a Hemicellulose-Derived Platform. Ind. Eng. Chem. Res. 2020, 59, 19876-19883.

(35) Kainulainen, T. P.; Hukka, T. I.; Özeren, H. D.; Sirviö, J. A.; Hedenqvist, M. S.; Heiskanen, J. P. Utilizing Furfural-Based Bifuran Diester as Monomer and Comonomer for High-Performance Bioplastics: Properties of Poly(Butylene Furanoate), Poly(Butylene Bifuranoate), and Their Copolyesters. Biomacromolecules 2020, 21 (2), 743-752.

(36) Lotzs, M.; Kandel, K.; Salciccioli, M.; Cohn, S.; Galuska, A. A.; Guzman, J.; Turner, S. R.; Edling, H. E.; Paschke, E. Bifuran-Modified Polyesters. USWO 2020106511 A1, 2020.

(37) Farah, S.; Kunduru, K. R.; Basu, A.; Domb, A. J. Molecular Weight Determination of Polyethylene Terephthalate. In Poly(Ethylene Terephthalate) Based Blends, Composites and Nanocomposites, 1st ed.; Visakh, P. M., Liang, M., Eds.; William Andrew: Norwich, NY, 2015; pp 143-165.

(38) Abdul Khalil, H. P. S.; Saurabh, C. K.; Syakir, M. I.; Nurul Fazita, M. R.; Bhat, A.; Banerjee, A.; Fizree, H. M.; Rizal, S.; Tahir, P. M. Barrier Properties of Biocomposites/Hybrid Films. In Mechanical and Physical Testing of Biocomposites, Fibre-Reinforced Composites and Hybrid Composites, 1st ed.; Jawaid, M., Thariq, M., Saba, N., Eds.; Woodhead Publishing Series in Composites Science and Engineering; Elsevier: Amsterdam, Netherlands, 2018; pp 241-258.

(39) Ghaemy, M.; Mossaddegh, K. Depolymerisation of Poly(Ethylene Terephthalate) Fibre Wastes Using Ethylene Glycol. Polym. Degrad. Stab. 2005, 90 (3), 570-576.

(40) Goh, H. W.; Ali, S.; Abdullah, N.; Idris, A. Time, Temperature and Amount of Distilled Water Effects on the Purity and Yield of Bis(2-Hydroxyethyl) Terephthalate Purification System. Bull. Chem. React. Eng. Catal. 2015, 10 (2), 143-154.

(41) Terzopoulou, Z.; Karakatsianopoulou, E.; Kasmi, N.; Tsanaktsis, V.; Nikolaidis, N.; Kostoglou, M.; Papageorgiou, G. Z.; Lambropoulou, D. A.; Bikiaris, D. N. Effect of Catalyst Type on Molecular Weight Increase and Coloration of Poly(Ethylene Furanoate) Biobased Polyester during Melt Polycondensation. Polym. Chem. 2017, 8 (44), 6895-6908.

(42) Gubbels, E.; Jasinska-Walc, L.; Noordover, B. A. J.; Koning, C. E. Linear and Branched Polyester Resins Based on Dimethyl-2,5- 
Furandicarboxylate for Coating Applications. Eur. Polym. J. 2013, 49 (10), 3188-3198.

(43) Papageorgiou, G. Z.; Tsanaktsis, V.; Bikiaris, D. N. Synthesis of Poly(Ethylene Furandicarboxylate) Polyester Using Monomers Derived from Renewable Resources: Thermal Behavior Comparison with PET and PEN. Phys. Chem. Chem. Phys. 2014, 16 (17), 79467958.

(44) Shan, G.-F.; Yang, W.; Tang, X.-G.; Yang, M.-B.; Xie, B.-H.; Fu, Q.; Mai, Y.-W. Multiple Melting Behaviour of Annealed Crystalline Polymers. Polym. Test. 2010, 29 (2), 273-280.

(45) Stoclet, G.; Gobius Du Sart, G.; Yeniad, B.; De Vos, S.; Lefebvre, J. M. Isothermal Crystallization and Structural Characterization of Poly(Ethylene-2,5-Furanoate). Polymer 2015, 72, 165-176.

(46) Konstantopoulou, M.; Terzopoulou, Z.; Nerantzaki, M.; Tsagkalias, J.; Achilias, D. S.; Bikiaris, D. N.; Exarhopoulos, S.; Papageorgiou, D. G.; Papageorgiou, G. Z. Poly(Ethylene FuranoateCo-Ethylene Terephthalate) Biobased Copolymers: Synthesis, Thermal Properties and Cocrystallization Behavior. Eur. Polym. J. 2017, 89, 349-366.

(47) Aguilar-Vega, M. Structure and Mechanical Properties of Polymers. In Handbook of Polymer Synthesis, Characterization, and Processing, 1st ed.; Saldivar-Guerra, E., Vivaldo-Lima, E., Eds.; John Wiley \& Sons: New York, 2013; pp 425-434.

(48) Menard, K. P.; Menard, N. R. Dynamic Mechanical Analysis in the Analysis of Polymers and Rubbers. Encycl. Polym. Sci. Technol. 2015, No. 9, 1-33.

(49) Foreman, J.; Sauerbrunn, S. R.; Marcozzi, C. L. Investigating the Sensitivity of Thermal Analysis Methods to Glass Transition. Int. Polym. Sci. Technol. 2011, 38 (6), 29-36.

(50) Siracusa, V. Food Packaging Permeability Behaviour: A Report. Int. J. Polym. Sci. 2012, 2012, 1-11.

(51) Huang, Y.; Paul, D. R. Physical Aging of Thin Glassy Polymer Films Monitored by Gas Permeability. Polymer 2004, 45 (25), 83778393.

(52) Murphy, T. M.; Freeman, B. D.; Paul, D. R. Physical Aging of Polystyrene Films Tracked by Gas Permeability. Polymer 2013, 54 (2), 873-880

(53) Polymer Blends Handbook, 2nd ed.; Utracki, L. A., Wilkie, C. A., Eds.; Springer: New York, 2014.

(54) Swaidan, R.; Ghanem, B.; Litwiller, E.; Pinnau, I. Physical Aging, Plasticization and Their Effects on Gas Permeation in "Rigid" Polymers of Intrinsic Microporosity. Macromolecules 2015, 48 (18), 6553-6561.

(55) Chen, H.; Liu, H.; Chen, M.; Ge, P.; Chen, S.; Yuan, H. Preparation of Thermostable and Compatible Citrate-Based Polyesters for Enhancing the Ultraviolet Shielding Performance of Thermoplastic Resin. Polym. Chem. 2021, 12 (13), 1939-1949. 